\title{
HOW REALISM PROMOTES BETTER SOCIAL OUTCOMES THAN EMPIRICISM AND SUBJECTIVE IDEALISM
}

\begin{abstract}
This paper proposes a conceptual model that fosters interdisciplinary thinking and critical thinking by connecting the three main philosophical traditions that impact modern thinking - British empiricism, Continental Europe subjective idealism, and realism with their epistemological foundations and in combination with modern social disciplines: ethics, social responsibility, and political economy. Through a statistical analysis this paper shows which of the three epistemologies produces better social outcomes.
\end{abstract}

Keywords: Epistemology, British empiricism, Continental Europe subjective idealism, realism, phenomenology, spirituality, social disciplines, ethics, social responsibility, political economy, values

1. The conceptual model. 2. The impact of social disciplines according to their epistemologies. 3. The independent variables of the statistical analysis: cultural values. 4. The dependent variables of the statistical analyses: social outcomes. 5. Statistical analysis based on Data Mining (Machine Learning). 6. Conclusions.

\section{THE CONCEPTUAL MODEL}

Modern civilization has received a profound legacy from three philosophical traditions: British empiricism, Continental Europe subjective idealism, and realism. These three philosophical traditions are connected with a variety of modern theories in three social sciences: ethics, social responsibility, and political economy.

In order to understand the social impact of these philosophical traditions, this paper proposes a conceptual model that classifies the main theories in these social disciplines according to their epistemological foundations. 

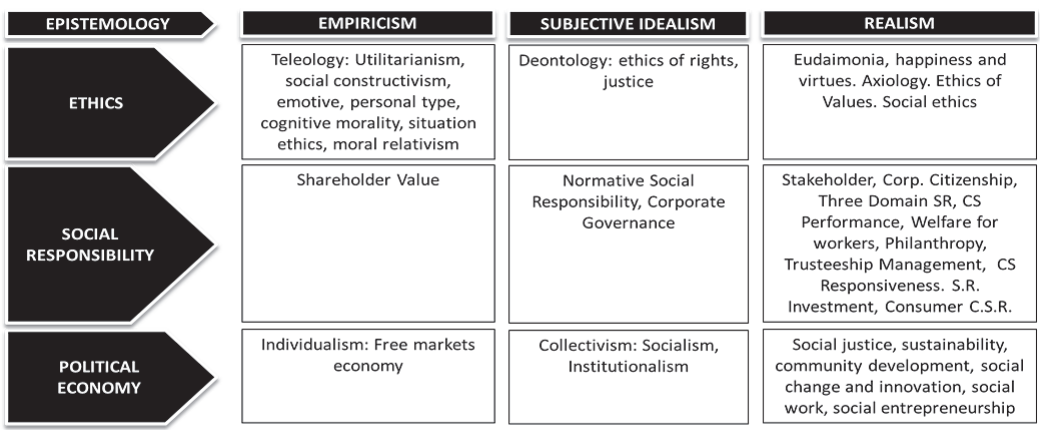

Fig. 1: The conceptual model

In this diagram, the first row reflects the three main epistemologies and the next three rows reflect the three social disciplines mentioned above.

- Empiricism: the view that all knowledge originates in experience.

- Subjective idealism: the view that reality lies in consciousness or reason.

- Realism: the view that things have an objective reality, ontologically independent of our perceptions, reason, and beliefs.

The first column reflects the approaches in modern social disciplines founded on empiricism, with a strong presence in the intellectual tradition known as British empiricism: e.g. utilitarian ethics and the notion that ethical decisions must be based on the maximization of pleasure and the minimization of pain, which is the backbone of the utility curves. These, in turn, lead to the demand and supply model, which forms the backbone of the shareholder value and social responsibility approach, and to free markets political economy.

The second column reflects the approaches in social disciplines founded on subjective idealism, with a strong presence in the intellectual tradition known as Continental Europe subjective 
idealism: e.g. universal deontological ethics, which leads to normative social responsibility and collectivist political economy.

The third column, realism, reflects the approaches in social disciplines connected to a eudemonic, axiological and social ethics, as well as to social responsibility and political economies oriented to the community.

This model has not yet received formal expression in the literature, probably due to the fact that the research in the last four centuries has tended to be very specialized, thus making interdisciplinary thinking uncommon. Nevertheless, ideas frequently align around the three epistemologies in the relevant literature.

\section{THE IMPACT OF SOCIAL DISCIPLINES ACCORDING TO THEIR EPISTEMOLOGIES}

What are the social consequences of the disciplines built upon the three main epistemologies discussed in this work: empiricism, subjective idealism, and realism? Which system of thought produces better social effects?

This section illustrates the associations between cultural values and a set of social indicators:

- the cultural values rely on the World Values Survey ${ }^{1}$ (e.g. good or harmful competition, self-expression as important for children, it is justifiable to cheat on taxes, etc.)

- the set of social indicators used are: GDP per capita, human development, individual freedom, transparency, and knowledge.

1 World Values Survey 2016, Institute for Comparative Survey Research, www.worldvaluessurvey.org [accessed on 31 July 2017]. 
No literature has been found that answers the question above. The closest relevant research is a study by Christian Welzel $^{2}$ carried out over the course of three decades and published in Freedom Rising: Human Empowerment and the Quest for Emancipation, together with the Institute for Comparative Survey Research. Welzel's approach, however, is different from the approach of this article, in that Welzel does not seek to discuss specifically the social effects of the three cultural values linked with the three epistemologies, nor their philosophical foundations.

\section{THE INDEPENDENT VARIABLES OF THE STATISTICAL ANALYSIS: CULTURAL VALUES}

The World Values Survey website states that they are "a global network of social scientists studying changing values and their impact on social and political life, led by an international team of scholars, with the WVS association and secretariat headquartered in Stockholm, Sweden. The survey, which started in 1981, seeks to use the most rigorous, high-quality research designs in each country. The WVS consists of nationally representative surveys conducted in almost 100 countries which contain almost 90 percent of the world's population, using a common questionnaire. The WVS is the largest non-commercial, cross-national, time series investigation of human beliefs and values ever executed, currently including interviews with almost 400,000 respondents. Moreover the WVS is the only academic study covering the full range of global variations, from very poor to very rich countries, in all of the world's major cultural zones."3

"The WVS seeks to help scientists and policy makers understand changes in the beliefs, values and motivations of people throughout

2 C. Welzel, Freedom Rising: Human Empowerment and the Quest for Emancipation, Cambridge University Press, New York 2014.

3 World Values Survey, op. cit. 
the world. Thousands of political scientists, sociologists, social psychologists, anthropologists and economists have used these data to analyze such topics as economic development, democratization, religion, gender equality, social capital, and subjective well-being. These data have also been widely used by government officials, journalists and students, and groups at the World Bank have analyzed the linkages between cultural factors and economic development." 4

\section{THE DEPENDENT VARIABLES OF THE STATISTICAL ANALYSES: SOCIAL OUTCOMES}

What are the effects of the cultural values considered on social outcomes by country?

- GDP (Gross Domestic Product) per capita ${ }^{5}$ as a proxy indicator of wealth.

- The Human Development Index ${ }^{6}$ (HDI), published by the United Nations Development Programme, incorporates income per capita, life expectancy, and education. The HDI was developed by Amartya Sen and Mahbub ul Haq.

- The Index of Economic Freedom ${ }^{8}$ was developed by The Heritage Foundation and The Wall Street Journal,

4 Ibidem.

5 GDP per capita, https://data.worldbank.org/indicator/NY.GDP.MKTP.CD?view=map [accessed on 31 July 2017].

6 The Human Development Index (HDI), United Nations Development Programme, Human Development Reports, http://hdr.undp.org/en/content/human-development-index-hdi [accessed on 31 July 2017].

7 According to the United Nations Development Programme, Human Development Reports: "The human development approach, developed by the economist Mahbub UI Haq, is anchored in Amartya Sen's work on human capabilities, often framed in terms of whether people are able to »be « and »do « desirable things in life."

8 The Index of Economic Freedom, The Heritage Foundation and The Wall Street Journal. Available at their website: http://www.heritage.org/index/about [accessed on 31 July 2017]. The Index states: "Today, we live in the most prosperous time in human history. Poverty, sicknesses, and ignorance are receding throughout the world, due in large part 
to measure the degree of economic freedom worldwide. The Index covers 12 freedoms in 186 countries according to the following four categories. Rule of Law: property rights, freedom from corruption. Limited Government: fiscal freedom, government size/spending. Regulatory Efficiency: business freedom, labor freedom, monetary freedom. Open Markets: trade freedom, investment freedom, financial freedom.

- The Political Freedom Index ${ }^{9}$ was developed by the Freedom House. For 195 countries and 14 territories, "[f]reedom in the World analyzes the electoral process, political pluralism and participation, the functioning of the government, freedom of expression and of belief, associational and organizational rights, the rule of law, and personal autonomy and individual rights".

to the advance of economic freedom. In 2017, the principles of economic freedom that have fueled this monumental progress are once again measured in the Index of Economic Freedom, an annual guide published by The Heritage Foundation, Washington's No. 1 think tank. For over twenty years the Index has delivered thoughtful analysis in a clear, friendly, and straight-forward format. With new resources for users and a website tailored for research and education, the Index of Economic Freedom is poised to help readers track over two decades of the advancement in economic freedom, prosperity, and opportunity and promote these ideas in their homes, schools, and communities."

9 Political Freedom Index, The Freedom House. Available at their website: https://freedomhouse.org/report-types/freedom-world [accessed on 31 July 2017]. The Index states: "Freedom in the World is Freedom House's flagship annual report, assessing the condition of political rights and civil liberties around the world. It is composed of numerical ratings and supporting descriptive texts for 195 countries and 14 territories. Freedom in the World has been published since 1973, allowing Freedom House to track global trends in freedom over more than 40 years. It has become the most widely read and cited report of its kind, used on a regular basis by policymakers, journalists, academics, activists, and many others. External analysts assess the 209 countries and territories, using a combination of on-the-ground research, consultations with local contacts, and information from news articles, nongovernmental organizations, governments, and a variety of other sources. Expert advisers and regional specialists then vet the analysts' conclusions. The final product represents the consensus of the analysts, advisers, and Freedom House staff." 
- The Human Freedom Index ${ }^{10}$, according to the Cato Institute, "presents the state of human freedom in the world based on a broad measure that encompasses personal, civil, and economic freedom."

- The Corruption Perceptions Index ${ }^{11}$ (CPI) developed by Transparency International ranks countries ,by their perceived levels of corruption, as determined by expert assessments and opinion surveys. The CPI currently ranks 177 countries on a scale from 100 (very clean) to 0 (highly corrupt)."

- The Knowledge Index ${ }^{12}$ is compiled by the World Bank Institute. "The Knowledge Index is the average of the rankings of the performance of a country or region in three areas

10 The Human Freedom Index, The Cato Institute, the Fraser Institute, and the Liberales Institut at the Friedrich Naumann Foundation for Freedom. Available at their website: https://www.cato.org/human-freedom-index [accessed on 31 July 2017]. The Index states: "Human freedom is a social concept that recognizes the dignity of individuals and is defined here as negative liberty or the absence of coercive constraint. Because freedom is inherently valuable and plays a role in human progress, it is worth measuring carefully. The Human Freedom Index is a resource that can help to more objectively observe relationships between freedom and other social and economic phenomena, as well as the ways in which the various dimensions of freedom interact with one another."

11 Corruption Perceptions Index, Transparency International. Available at their website: https://www.transparency.org/research/cpi/overview [accessed on 31 July 2017]. The Index states: "From villages in rural India to the corridors of power in Brussels, Transparency International gives voice to the victims and witnesses of corruption. We work together with governments, businesses and citizens to stop the abuse of power, bribery and secret deals. As a global movement with one vision, we want a world free of corruption. Through chapters in more than 100 countries and an international secretariat in Berlin, we are leading the fight against corruption to turn this vision into reality."

12 The Knowledge Index, World Bank Institute. According to this report: "The World Bank Institute's Knowledge for Development Program (K4D) helps client countries build their capacity to access and use knowledge to strengthen their competitiveness and increase their economic and social well-being. The program works with clients to design and develop realistic and achievable knowledge-based development strategies. It helps countries assess how they compare with others in their ability to compete in the knowledge economy and to identify appropriate policies to help them achieve their goals. K4D also offers recommendations for policy reform on the knowledge economy accompanied by 
of the so-called Knowledge Economy, namely, education, innovation and information and communications technology." The Index measures the following indicators: "Secondary enrolment: students enrolled at the secondary level of education; Tertiary enrolment: students enrolled in at the tertiary level of education, i.e., college, university or technical school; Researchers in R\&D: people engaged in research and development; Patent applications: patent applications granted by the United States Patent and Trademark Office (USPTO); Scientific and technical journal articles: articles published in journals on physics, biology, chemistry, mathematics, clinical medicine, biomedical research, engineering and technology, and earth and space sciences; Telephones: telephone mainlines and mobile phones; computers: personal computers, i.e., selfcontained computers designed to be used by a single individual; Internet users: people with access to the worldwide network."

\section{STATISTICAL ANALYSIS BASED ON DATA MINING (MACHINE LEARNING)}

Why do we need to rely on data mining instead of using the more traditional linear correlation? A correlation analysis is not a good statistical tool because it indicates a linear association between two variables, but many variables may not have such a linear association. For example, what is the relationship between cultural values that place great importance on state intervention and the Human Development Index?

If one lived in a nation with no state at all, one would be governed by the law of the jungle and this would lead to low human development. Some degree of state intervention may provide some

complementary advice on what the country needs to do to develop appropriate capacity to deliver on these policies." 
social organization, leading to higher human development. However, a massive state intervention that eliminates all personal freedoms, for instance when government takes over all economic activities, resembles a communist tyranny and would lead to low human development again. Thus, there not a linear correlation between state intervention and human development.

Therefore, in order to explore further associations between these two variables without the limitations of the correlations, we decided to conduct an exploratory analysis using recursive partitioning, which is an exploratory data mining technique (also known as regression trees). For more information on data mining and recursive partitioning, the reader may consult James, Witten, Hastie, and Tibshirani. ${ }^{13}$ As the name implies, recursive partitioning splits data into homogeneous bins so that the values of the outcome (such as the GDP per capita) are homogeneous within the bin. An advantage of recursive partitioning is that it does not depend on the common statistical assumptions such as the linear (or researcher-specified) association between variables. Another advantage is that researchers can select a large number of variables to be explored simultaneously, and the algorithm itself finds the variables with the highest predictive power while discarding variables that are not associated with the outcome. A method called random forest does this recursive partitioning repeatedly, which commonly results in higher predictive power than the traditional statistical methods such as regression or correlations.

It should be noted that data mining methods (random forest in particular, which was the method that we selected) are purely exploratory in nature. These are tools used to explore which variables have the highest predictive power for each of the outcomes.

The plots below show the variables that had the highest predictive power for GDP. Each item is labeled with an E (empiricist), I (idealist),

13 G. James, D. Witten, T. Hastie, R. Tibshirani, An Introduction to Statistical Learning with Applications, in: R. Springer Texts in Statistics 2013. 
or R (realist), so that the reader can identify which variables belong to each ideology.

The highest-scoring variables on the Importance axis are the ones with the highest predictive power. Notice that the main variables are arranged on the horizontal axis from the most important to the least important. The most important variables are on the left of the "elbow", and in this case they are the first three variables.

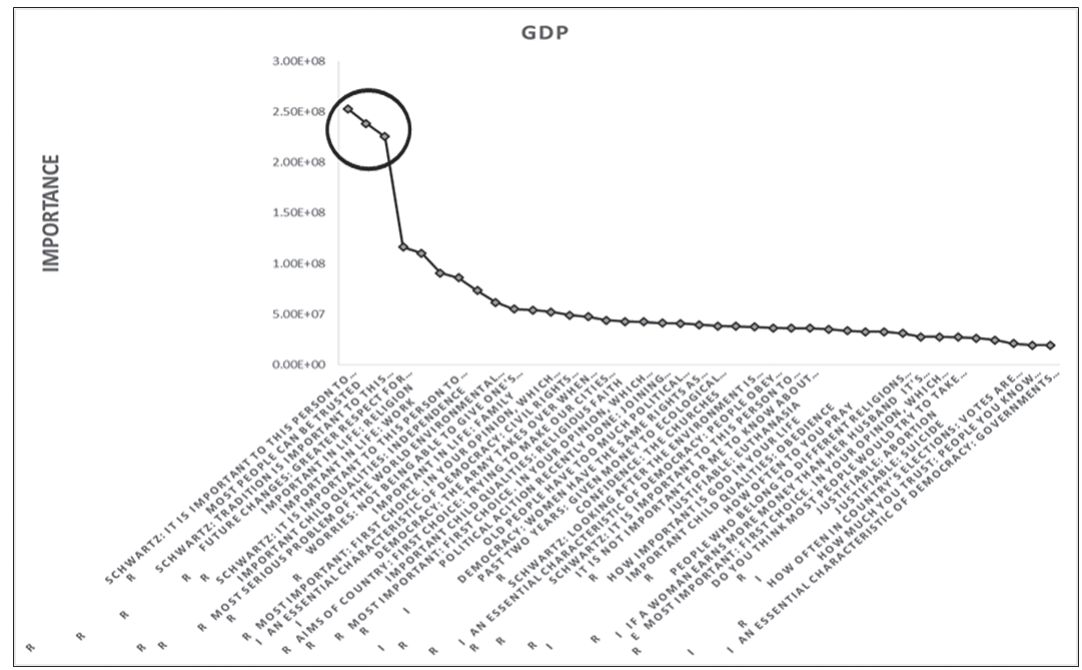

Fig. 2: Predictive power of each cultural value for GDP per capita

The only prediction coefficients that matter for data mining are the first ones on the left of the elbow of the curve. The next coefficients indicate a poor predicting power.

The first three items in the above graph, which were found to have the highest predictive power, fall under the umbrella of realistic values: 
- Realist. Schwartz: it is important to a person to always behave properly and avoid doing anything people would consider wrong.

- Realist. Most people can be trusted.

- Realist. Schwartz: tradition is important to a person; it is important to follow the customs handed down by one's religion or family.

Similar conclusions can be found following data mining and statistical analysis for the other social outcomes:

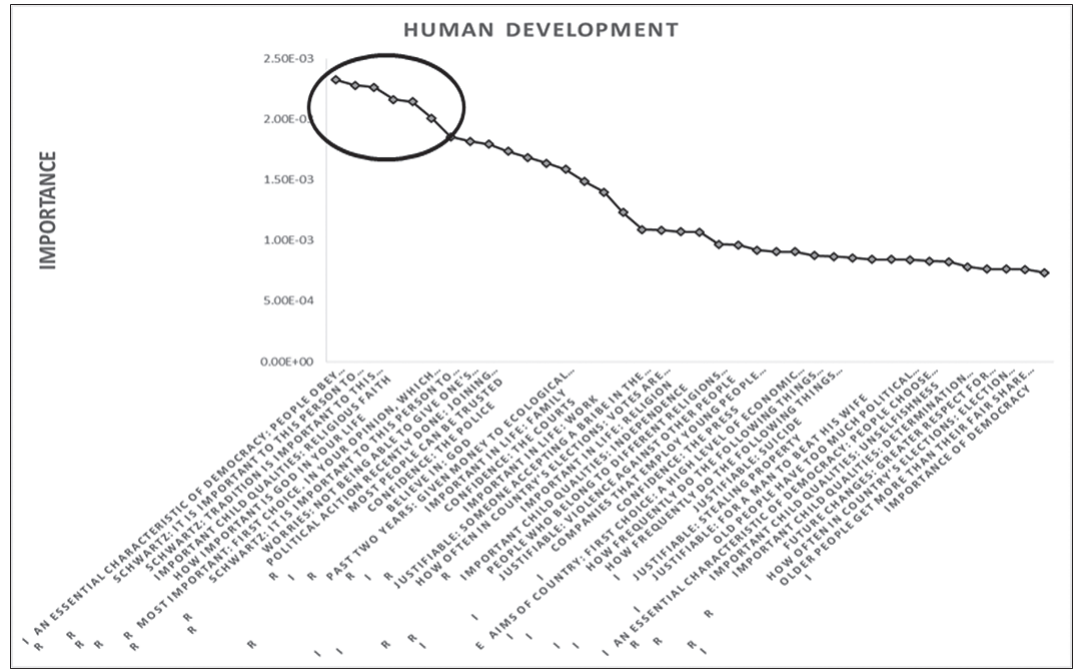

Fig. 3: Predictive power of each cultural value for Human Development

- Idealist. Democracy: people obey their rulers.

- Realist. Schwartz: it is important to a person to always behave properly and avoid doing anything people would consider wrong. 
- Realist. Schwartz: tradition is important to a person; it is important to follow the customs handed down by one's religion or family.

- Realist. Qualities that are important in children: religious faith.

- Realist. How important is God in your life?

- Realist. Willingness to fight for your country.

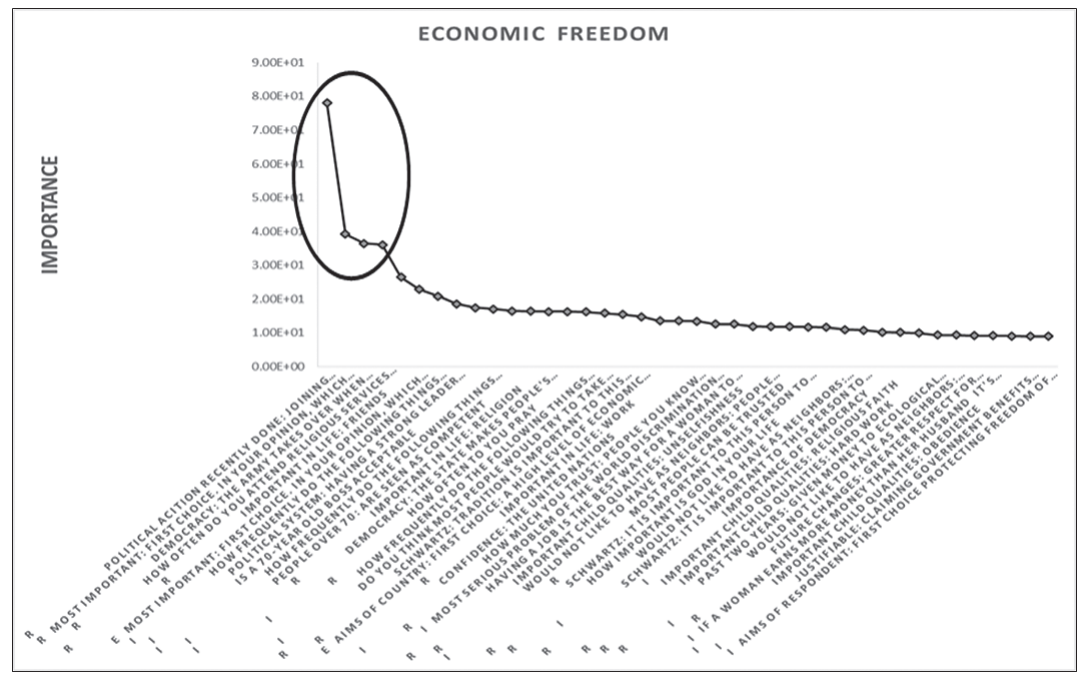

Fig. 4: Predictive power of each cultural value for Economic Freedom

- Realist. Political action recently taken: joining strikes.

- Realist. Most important choice: first choice. The fight against crime.

- Realist. Democracy: the army takes over when government is incompetent.

- Realist. How often do you attend religious services? 


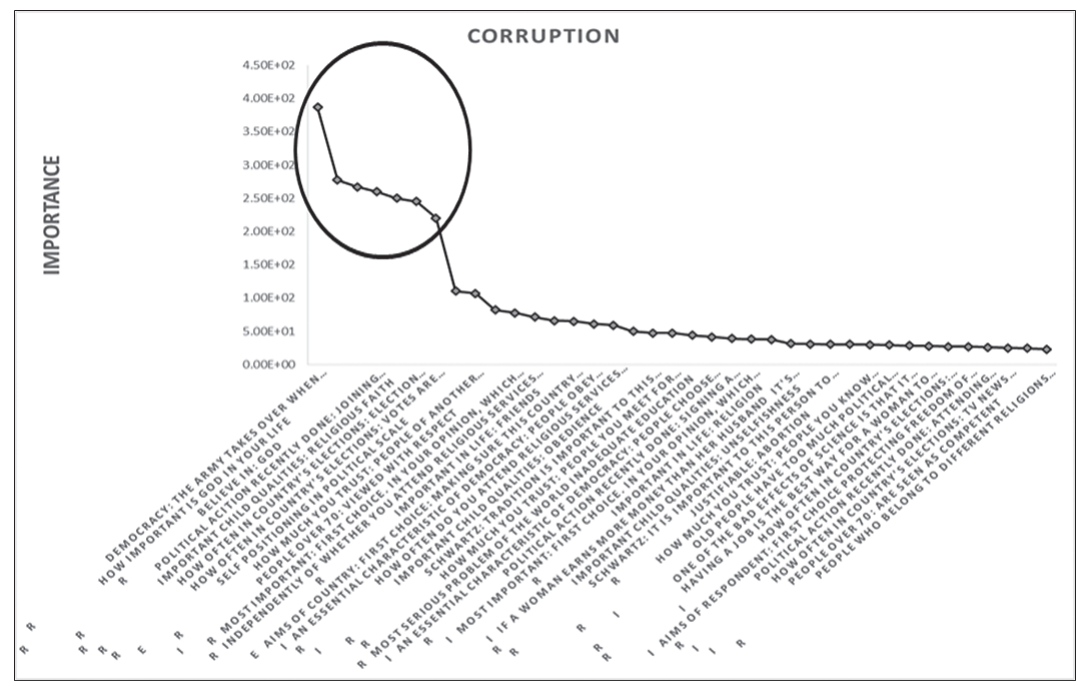

Fig. 5: Predictive power of each cultural value for Corruption

- Realist. Democracy: the army takes over when government is incompetent.

- Realist. How important is God in your life?

- Realist. Believe in: God.

- Realist. Political action recently taken: joining strikes.

- Realist. Qualities that are important in children: religious faith.

- Realist. How often in a country's elections: election officials are fair.

- Realist. How often in a country's elections: votes are counted fairly. 


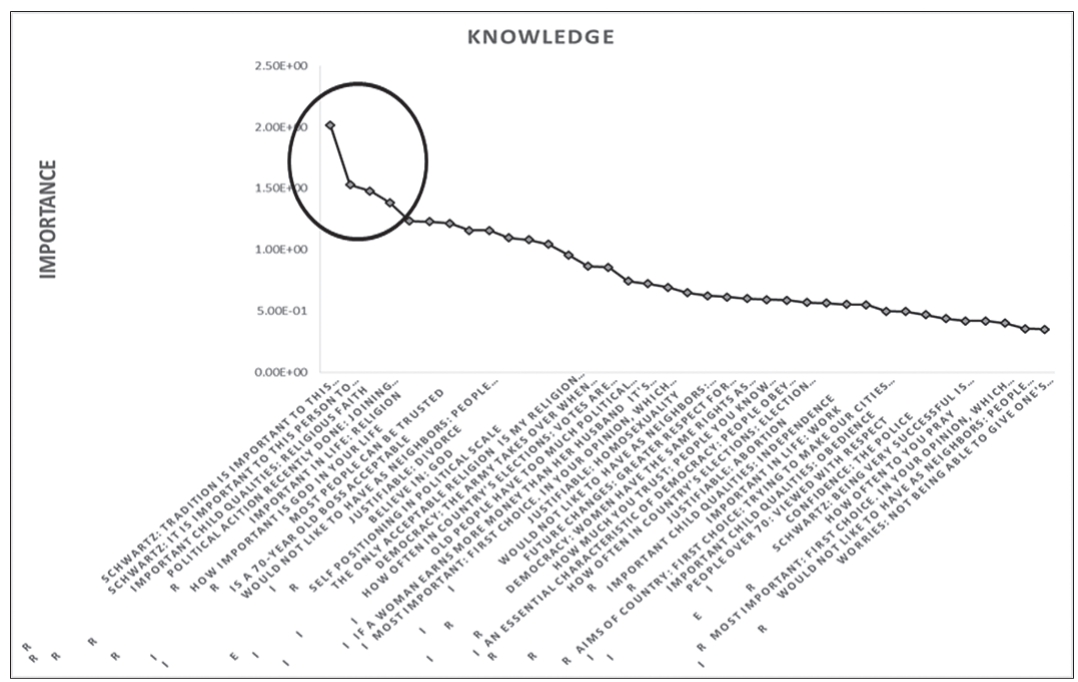

Fig. 6: Predictive power of each cultural value for Knowledge

- Realist. Schwartz: tradition is important to a person; it is important to follow the customs handed down by one's religion or family.

- Realist. Schwartz: it is important to a person to always behave properly and avoid doing anything people would consider wrong.

- Realist. Qualities that are important in children: religious faith.

- Realist. Political action recently taken: joining strikes.

- Empiricist. Justifiable: divorce.

\section{CONCLUSIONS}

The conceptual model presented above proves to be useful to classify and integrate social disciplines according to their epistemological foundations. 
The statistical analysis indicates that there is an important difference in the social impact of the cultural values of the 60 countries considered, depending on which particular epistemology provides the foundations for the three social disciplines analyzed. This result gives further consistency to the model.

The statistical analysis also shows that the social impact of realism is better than the social impact of empiricism and subjective idealism.

An earlier paper explained that realism generates better social results than the other two epistemologies because it fosters a transformation process of individuals and communities, thus promoting social leadership. Hence the better social outcomes in the statistical analysis.

Benefits of this research and contributions to modern thinking

1. Interdisciplinary thinking as a source of wisdom and social leadership
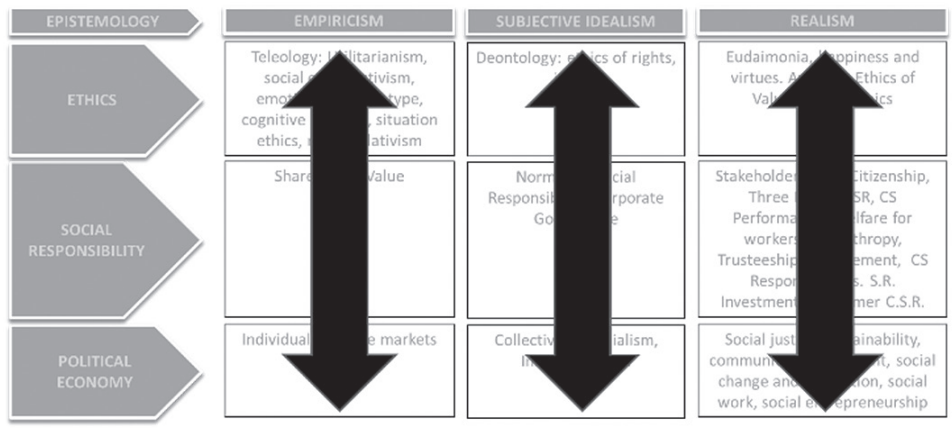

The conceptual model presented above introduces interdisciplinary thinking, connecting modern social disciplines with their philosophical and epistemological foundations. This enables us to return to a holistic methodology that we have lost as a result of the atomization of knowledge initiated after Descartes. Interdisciplinary thinking fosters wisdom, knowledge integration, individual integration, communities integration, discernment, and social leadership. In turn, this should have a positive impact on individuals, communities, 
businesses and government organizations, as well as on society as a whole.

2. Critical thinking
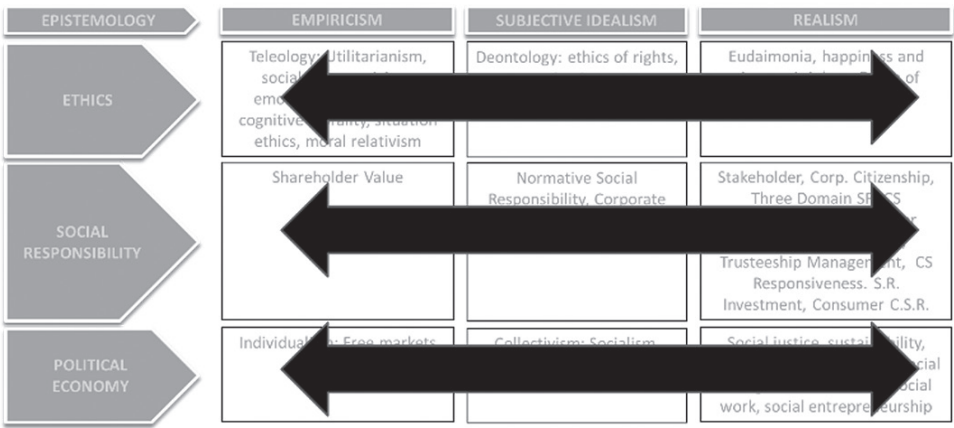

Both the conceptual model and the statistical analysis are an excellent source of critical thinking. Each ethical approach, theory of social responsibility, and political economy model has an epistemological foundation that is responsible for its specific social impact. This enables us to see the social disciplines in perspective and understand the good and bad consequences that each of them may generate.

3. The benefits of realism to foster a transformation process towards social leadership
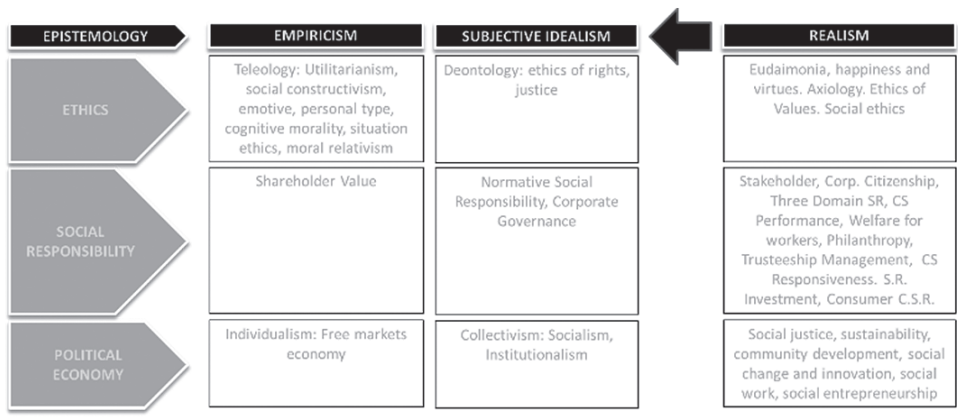
The extraordinary contributions of realism and phenomenology in developing a better epistemology, metaphysics, religion, and system of values, facilitate the transformation of individuals and communities and foster discernment. This, in turn, promotes social leadership. and helps us build a better world.

Limitations of this research

The conceptual model presented in this paper has some limitations.

- Difficulties with the epistemologies

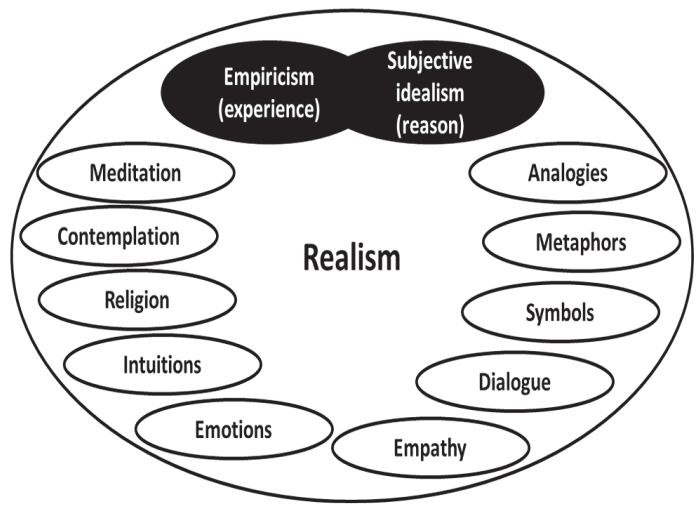

Fig. 7: Sources of knowledge of the three epistemologies

The three epistemologies may not be completely separated. Realism may involve empiricism and subjective idealism, together with other sources of knowledge. Although subjective idealism is intended to be completely different from empiricism, it is not so clear that such a separation is entirely possible: how can idealist knowledge exist without previous empirical knowledge?

- Problems with the classification of thinkers, disciplines, theories, ideas, and values under each epistemology

The non-excludability thesis presents some challenges for this paper. 
The classification of thinkers, disciplines, theories, ideas, and values under each epistemology is complex because in many cases we do not rely on one single epistemology: philosophical ideas are not always classifiable as purely empiricist or subjective idealist or realist. In many cases, they are not exclusively grounded in a single philosophical tradition.

For example, the modern right of non-discrimination should be considered an empirical achievement according to Hobbes' social contract and Kant's account of human rights; a law administered by a state as a result of the cosmic "geist", Hegel's universal reason or spirit; or it can be the result of a realist social leadership generated by the values of the community. Thus, the same outcome is classified differently as a result of the three different epistemologies.

It is worth noticing that, although this challenge may impact the statistical analysis, most of the variables considered is better classified under one specific philosophical tradition.

Furthermore, this challenge reinforces the validity of the model. Continental Europe subjective idealism was born as a reaction to the limitations of British empiricism. In that regard, Hobbes, probably following Hegel's logic, acted as a subjective idealist when he proposed the social contract as a natural historical evolution, and application of Hegel's universal reason or "geist" to our daily lives. Our conceptual model helps understand that the British empiricism label that most attach to Hobbes is limited, because in proposing the social contract he acted as a Continental Europe subjective idealist.

Another challenge that reinforces the validity of our conceptual model is the fact that some values may fall under the three epistemologies. For example, the "Income equality" category in the survey should be classified under subjective idealism when it is understood in a radical sense. However, to a moderate degree it can be a realist value. This confirms that a linear correlation makes sense for idealist values, but not for realist values. Showing how realism 
looks for balance, whereas subjective idealism does not, also provides crucial confirmation of the validity of our conceptual model.

Although there is room for debates and discrepancies, it is healthy that such debates exist as this is the beginning of critical thinking and discernment, which are a central goal of this paper.

\section{REFERENCES}

Corruption Perceptions Index, Transparency International, https://www.transparency.org/research/cpi/overview.

GDP per capita, https://data.worldbank.org/indicator/NY.GDP.MKTP.CD? view=map.

James G., Witten D., Hastie T., Tibshirani R., Daniela W., Hastie, Trevor; Tibshirani, Robert. An Introduction to Statistical Learning with Applications, in: R. Springer Texts in Statistics 2013.

Political Freedom Index, The Freedom House, https://freedomhouse.org/ report-types/freedom-world.

The Human Development Index (HDI), United Nations Development Programme. Human Development Reports, http://hdr.undp.org/en/content/ human-development-index-hdi.

The Human Freedom Index, The Cato Institute, the Fraser Institute, and the Liberales Institut at the Friedrich Naumann Foundation for Freedom, https:// www.cato.org/human-freedom-index.

The Index of Economic Freedom, The Heritage Foundation and The Wall Street Journal, http://www.heritage.org/index/about.

The Knowledge Index, World Bank Institute, http://web.worldbank.org/archive/ website01030/WEB/IMAGES/KAM_V4.PDF.

Welzel C., Freedom Rising: Human Empowerment and the Quest for Emancipation, Cambridge University Press, New York 2014.

World Values Survey 2016, Institute for Comparative Survey Research, www. worldvaluessurvey.org.

Juan Pablo Stegmann

juan.stegmann@umuc.edu

University of Maryland University College

3501 University Blvd. East, MD 20783 Adelphi, USA

DOI: 10.21697/spch.2019.55.3.05 